\title{
Postage stamps as a health promotion tool in the Nepalese community
}

\author{
T. Pramanik, ${ }^{1}$ S. Pramanik ${ }^{2}$ and R. Chanda ${ }^{2}$
}

SUMMARY Over the last 15 years the government of Nepal has issued postage stamps as a way of raising awareness of health issues in the general population and especially in remote communities. The topics covered by 8 different stamps are good child health care practices, combating drug abuse, hazards of smoking, prevention of AIDS, prevention of blindness due to cataract, fighting cancer and rehabilitation of disabled people.

\section{Introduction}

Health education is an essential tool of community health to inform and motivate people to adopt and maintain healthy practices and lifestyles. To increase awareness of the curability and preventability of certain diseases among the general public, mass media such as television, newspapers and posters are generally employed [1]. Another innovative method of health promotion that reaches every member of the population are postage stamps. We show here a collection of postage stamps that have been issued in the last 15 years by the government of Nepal postal services department, the Nepal Philatelic Bureau in Kathmandu.

\section{The stamps}

Eight stamps have been published with a message about public health, using pictures and slogans in both Nepalese and English (Figure 1). The topics covered are: child health care (2), drug abuse (1), smoking hazards (1), fighting cancer (1), prevention of AIDS (1), prevention of blindness due to cataract (1) and rehabilitation of disabled people (1).

\section{Childcare}

In order to promote standard recommendations $[1,2]$ for the improvement of childcare and immunization in Nepal, a 1rupee stamp with the message "Save and develop the children" was published in 1989. Four pictures illustrate good childcare practices: breastfeeding, weighing the child, immunization of a child and giving oral rehydration solution to a sick child. In another 1 rupee stamp published in 1994, the picture shows a nurse administering polio drops to a child in a primary health centre.

Drug abuse, smoking and cancer

Drug abuse is a preventable chronic relapsing disease and continuous mass me-

${ }^{1}$ Department of Clinical Physiology, Nepal Medical College, Jorpati, Kathmandu, Nepal.

${ }^{2}$ Department of Physiology, Vidyasagar College, Calcutta, India.

Received: 03/07/03; accepted: 18/08/03

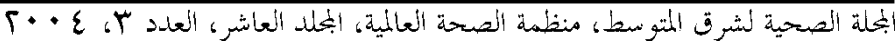




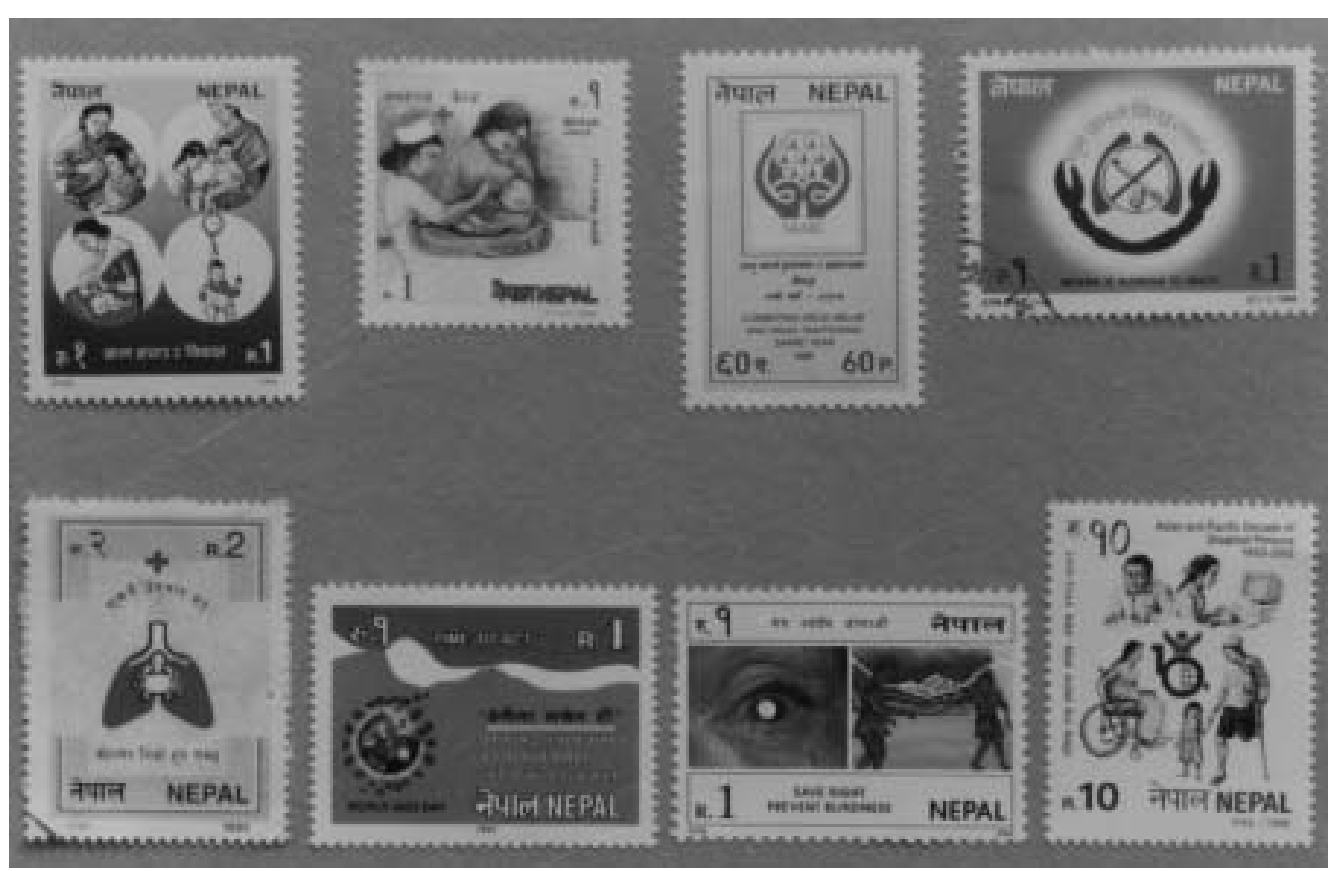

Figure 1 Collection of Nepalese postage stamps with health promotion messages

dia campaigns are needed to highlight the consequences of drug addiction [3]. A 60paise postage stamp was published with the slogan, "Combating drug abuse drug trafficking SAARC year 1989" and the logo of the South Asian Association for Regional Cooperation (SAARC).

At present, about 4 million people a year die of tobacco-related diseases and current trends could result in 8.4 million annual deaths by the late 2020s [4]. A 1-rupee postage stamp was published in 1994 with the message "Smoking is injurious to health". This has an illustration showing a "No smoking" logo with a picture of a heart and symbolic representation of lungs, and below it the zodiac symbol for Cancer the crab. Above it is written "Smoking takes away life".
Certain forms of cancer are amenable to surgical removal, while others respond favourably to radiation or chemotherapy or both [1]. A 2-rupee postage stamp was published in 1995 worth with the slogan "If treated early cancer can be cured". This stamp has picture of lungs with a symbolic representation of cancer and a red cross on the top of the figure.

\section{HIV/AIDS}

Around the world, the many early community-based HIV/AIDS prevention programmes were based on the assumption that self-awareness of risk behaviour and knowledge about modes of transmission were sufficient to stop the spread of the virus [5]. In 1993, the government of Nepal

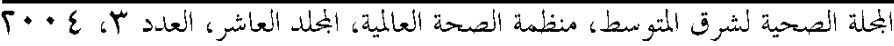


published a postage stamp worth 1 rupee with a message, "Be careful, use new needles for injection, avoid indiscriminate sex and use condoms". A picture shows the world surrounded by symbolical HIV virus, and the slogan "World AIDS Day".

\section{Disability}

Cataract accounts for $72 \%$ of cases of blindness in Nepal [1]. A commemoration 1-rupee postage stamp was issued in 1998 with the slogan "Save sight, prevent blindness" to make people aware of the curability of cataract through surgery. The stamp has 2 pictures: 1 showing cataract and another showing a person helping a blind person to cross the road.

Disability has been classified as a restriction or inability to perform an activity in the manner or within the range considered normal, depending on age, sex, social and cultural factors [6]. A resolution of the Economic and Social Commission for Asia and the Pacific (ESCAP) in 1992 declared the period 1993 to 2002 as the Asian and Pacific decade of disabled people. The pri- mary focus of the decade of action was the expansion of opportunities for the full participation of people with disabilities in society and their equality in the development process. The 10-rupee stamp with the title "Asian and Pacific Decade of Disabled Persons 1993-2002" was published in 1998 to commemorate the decade. It shows a disability symbol and 4 disabled people at their work.

\section{Discussion}

Although modern modes of electronic communication such as telephones and email are available in the cities and towns of Nepal, these are less common in the remote areas of the country. Most people still make use of the postal system. We believe that using postage stamps with pictures and slogans to promote different aspects of health is a useful method to inform the general public about various health problems and prevention.

\section{References}

1. Park K. Park's textbook of preventive and social medicine. Jabalpur, India, Banarsidas Bhanot Publishers, 1997.

2. Claeson M, Waldman RJ. The evaluation of child health programmes in developing countries: from targeting diseases to targeting people. Bulletin of the World Health Organization, 2000, 78(10): 1234-45.

3. Qureshi NA, Al-Ghamdy YS, Al-Habeeb TA. Drug addiction: a general review of new concepts and future challenges. Eastern Mediterranean health journal, 2000, 6(4):723-33.
4. Kaufman N, Yach D. Tobacco controlchallenges and prospects. Bulletin of the World Health Organization, 2000, 78(7): 867.

5. Tarantola D. Reducing HIV/AIDS risk impact and vulnerability. Bulletin of the World Health Organization, 2000, 78(2): 236-7.

6. Barbotte $E$ et al. Prevalence of impairments, disabilities, handicaps and quality of life in the general population: a review of recent literature. Bulletin of the World Health Organization, 2001, 79(11):1047-55. 